\title{
Neue Coleopteren aus Syrien und Marocco.
}

\author{
Von
}

Edm. Reitter in Mödling, bei Wien.

Tolyphus syriacus n. sp. Ovalis, convexus, nigro-aeneus, elytris magis metallico-nitidis, antennis pedibusque piceo-nigris, tarsis dilutioribus, prothorace antrorsum magis angustato, subtilissime, dorso obsolete punctulato, elytris striatis, striis duplicato-lineolatis, lineolis singulis internis minus impressis punctatis, stria prima antice singula, postice duplicata, secunda duplicata aequaliter, magis impressa; interstitiis subtilissime parce punctulatis, scutello laevi. Long. $2-3$ mill.

Dem Tol. granulatus sehr ähnlich, etwas kürzer oval, weniger lebhaft gefärbt, schwärzlich grün, die Flügeldecken gewöhnlich heller, oft mit einem Kupfer- und Bronze-Anfluge. Der Halsschild ist nach vorn stärker verengt und etwas schmäler als die Flügeldecken. Die Streifung der Flügeldecken ist ganz ähnlich, nur ist der erste Streifen neben der Naht nicht wie bei granulatus ganz einzeln, sondern von der Mitte zur Spitze, wie die andern Streifen, doppelt; der zweite aus zwei Doppellinien gebildete Streifen hat die innere Linie nicht wie die übrigen Streifen und wie bei granulatus viel seichter, sondern ist fast noch tiefer als die andern. Auf dem Halsschilde steht gewöhnlich jederseits an der Basis ein gröfserer Punkt, der seltener fehlt.

Syrien: Haifa. Scheint nicht selten zu sein.

Lithophilus latus n. sp. Latus, brevissime fulvo-pubescens, niger, ore, antennis, pedibus, abdomine sensim apice, prothorace elytrorum margine laterali tenuissime, prope humeros perparum latiore, apice late maculatim rufis; prothorace transverso, cordato, coleopteris angustiore, dense subtiliter, lateribus fortiter punctato, elytris latis, subovalibus, dense subtiliter sat profunde et inaequaliter punctatis. - Long. 3.5 mill.

Dem Lith. ovipennis ähnlich, etwas gröfser und in den Flügeldecken breiter, letztere nicht eiförmig, sondern oval, in der Mitte ziemlich parallel, schwarz, der Mund, die Fühler, Beine, der Halsschild, das Abdomen gegen die Spitze, der schmale Seitenrand der Flügeldecken, an den Schultern nur wenig breiter, lebhaft roth 
gefärbt. Die Spitze der Flügeldecken zeigt einen mehr gelbrothen, schrägen, gut abgegrenzten Flecken. Der Halsschild ist herzförmig, viel schmäler als die Flügeldecken, dicht und fein an den Seiten gröber punktirt. Flügeldecken breit, ähnlich wie bei connatus geformt, ziemlich stark gewölbt, dicht, mälsig fein, ungleich punktirt, indem kleinere und gröfsere Punkte zahlreich wechseln, die gröfseren Punkte sind aber weniger auffälig als bei andern Arten, an den Seiten sind sie etwas gröfser.

Von Lith. ovipennis durch die vorherrschend schwarze Färbung, schwarzen Kopf, Grölse u. s. w.; von Lith. cordicollis Guerin, aus Aegypten, mit dem sie in Gröfse und Körperform übereinstimmt, durch den Mangel von Spuren angedeuteter Streifen, dunklen Kopf und die grofse Apicalmakel der Flügeldecken verschieden.

Ist neben $L$. cordicollis $\mathrm{zu}$ stellen.

Haifa, in Syrien, von Lange entdeckt. Selten.

Lithophilus marginatus n. sp. Latus, sat longe fulvopubescens, rufus, elytris (margine laterali tenui-aequali rufa excepta) nigris, prothorace transverso, subcordato, ante basin valde sinuatim angustato, lateribus pone medio obtuse angulato, dorso parce subtilissime, lateribus fortiter sed minus profunde punctato, elytris thorace latioribus, lato-ovatis, dense subtiliter punctatis, punctis perparum majoribus intermixtis. - Long. 4 mill.

Dem L. cordicollis Guer. aus Aegypten sebr nahe stehend, ebenso grofs und von gleicher Form, gelbroth und nur die Flügeldecken bis auf einen schmalen gleichmäfsigen rothen Rand, schwarz. Die Behaarung ist länger und dichter, der Halsschild ist hinten viel stärker eingezogen und die Seiten bilden hinter der Mitte einen deutlichen stumpfen Winkel. Die Flügeldecken haben neben der Naht ebenfalls einige Spuren angedeuteter Streifen.

Beiruth in Syrien.

Atomaria laevis n. sp. Subovalis, fortiter convexa, nitida, subglabra (brevissime, vix perspicue fulvo-puberula) rufo-castanea, pedibus dilutioribus, antennarum articulis $4-8$ quadratis, clava triarticulala, his articulis duobus primis subquadratis; prothorace coleopteris latitudine, levissime transverso, antrorsum paullo magis attenuato, sat fortiter, minus dense punctato, angulis posticis fere rectis, subobtusis, basi subbisinuato, transversim impresso; elytris ovatis, valde convexis, parce subtilissime, apicem versus obsolete punctatis. - Long. 1.7 mill.

Der Atom. gibbula sehr ähnlich, jedoch einfarbig rostroth, der Halsschild breiter, und viel stärker als die Basis der Flügeldecken 
punktirt. Durch letztere Eigenschaft kommt sie in die Verwandtschaft der A. parvula, von der sie sich durch die Gröfse und hellere Färbung unterscheidet.

Syrien: Haifa; ron Hrn. Lange gesiebt.

Merophysia biplicata n. sp. Elongato-ovata, leviter convexa, obsolete puberula, testacea, antennis articulis 4,5 leviter oblongis, 6,7 quadratis, prothorace subquadrato, lateribus parum sinuato, basin versus haud magis angustato, ante medium latissimo, subtilissime punctato, prope basin depresso et utrinque plicato, elytris elongato ovatis, apice subacuminatim angustatis, subtiliter punctulatis. - Long. 1.5 mill.

Der M. carinulata sehr ähnlich, ebenfalls mit zwei Fältchen an der Basis des Halsschildes, jedoch viel kleiner, blasser gefärbt, von schmälerer Gestalt und vorzüglich durch die Fühler verschieden, deren viertes und fünftes Glied länger als breit, das sechste und siebente so lang als breit, bei carinulata $4-7$ durchaus gleich, fast kürzer als breit ist.

Haifa in Syrien.

Merophysia uniplicata n. sp. Elongato-ovata, leviter convexa, obsolete puberula, rufa, nitida, antennarum articulis 4-7 quadratis, prothorace vix transverso, subcordato, lateribus subdeflexis, haud explanalis, subtiliter punctato, basi medio impresso, impressione ante scutello per carinulam divisa; elytris oblongo-ovatis, distincte subtiliterque punctatis. - Long. 1.7 mill.

Mit M. carinulata, oblonga und foveolata verwandt; von allen durch das einzelne Fältchen an der Basis des Halsschildes unterschieden, welches sich über dem Schildchen befindet.

Marocco: Casablanca. (Quedenfeld.)

Cartodere laticeps n. sp. Elongata, leviter depressa, pilis albidis lanuginosis parce obtecta, rufa, antennis tarsisque testaccis; antennarum articulis intermediis subglobosis, non transversis, capite thorace vix angustiore, magno, latitudine parum longiore, confertim fortiter punctato, vertice postice canaliculato, ante oculos parvulos constricto; prothorace leviter transverso, depresso, confertim fortiter punctato, lateribus crenulato et submarginato, apicem versus leviter angustato, angulis posticis acuto-rectis, dorso prope latera longitudinaliter impresso, elytris thorace latioribus, elongato-ovatis, sutura lateribusque leviter, costisque tribus fortiter elevatis, costa intermedia antice subinterrupta, interstitiis biseriatim grosse punctatis, margine basali elevata cum costa prima et tertia connexa, humeris subangulatis. - Long. 1.5 mill. 
Von C. pilifera durch den grofsen Kopf, welcher dem Halsschilde an Breite nicht nachsteht, und den Halsschild, welcher an den Seiten fast gerade und dessen Hinterwinkel scharf rechtwinkelig oder spitzig sind; endlich durch die viel höheren Rippen der Flügeldecken verschieden.

Ich wäre geneigt gewesen, in dieser Art die mir unbekannte Cartodere inflaticeps Motsch. aus der Krimm zu vermuthen; dagegen spricht jedoch die Angabe über den langen Halsschild mit stumpfen Winkeln und das Vaterland.

Es liegen mir sechs Exemplare vor, welche von Hrn. Lange bei Haifa in Syrien gesammelt wurden.

Tenebrioides maroccanus n. sp. Piceus, subdepressus, pedibus obscure ferrugineis, capite prothoraceque sat fortiter parce punctatis, fronte obsolete sulcata, sulca postice (in medio capitis) subfoveolata, prothorace leviter transverso, basin versus angustato, lateribus subrecto, angulis anticis leviter productis, subacutis, posticis minutis rectis, lateribus parum subtiliter punctato, linea basali ante scutellum indistincte interrupta, fere integra; scutello minuto, oblongo, laevi; elytris subparallelis, pone medium perparum ampliatis, striatopunctatis, interstitiis subbiseriatim, subtiliter punctulatis, planis, subrugosis, humeris subdentatis, antennis brevibus, clava distincte triarticulata, articulis $1-8$ haud subserratis. - Long. 8 mill.

Casablanca, Marocco.

Dem T. mauritanicus täuschend ähnlich, jedoch durch die Fühler, welche nicht allmählig dicker werden und aufsen allmäblig aufschwellend gesägt erscheinen, sondern einfach sind und eine deutlich abgesetzte dreigliederige Keile besitzen, verschieden. Auf der Stirn ist das Grübchen deutlich; der Halsschild ist an der Basis fast vollständig gerandet u.s. w.

Lasioderma punctulata n. $\mathrm{sp}$. L. testaceae valde affinis sed dense distincteque punctata diversa; ovalis, convexa, ferruginea, breviter griseo-pubescens et pilis longioribus subseriatim dispositis intermixtis, prothoracis angulis posticis rotundatis, elytris quam in testacea longioribus. - Long. 1.2-1.8 mill.

Der L. testacea sehr ähnlich, von derselben Grölse, Gestalt und Färbung, nur sind die Flügeldecken länger, diese haben deutliche, längere Haarreihen und die ganze Oberseite ist sehr dicht und deutlich, dreimal stärker als bei L. testacea, punktirt.

Syrien, nicht selten. (Haifa.) 


\section{$2 \mathrm{BHL}$ Biodiversity Heritage Library}

Reitter, Edmund. 1884. "Neue Coleopteren aus Syrien und Marocco." Deutsche entomologische Zeitschrift 1884(1), 251-254.

https://doi.org/10.1002/mmnd.48018840107.

View This Item Online: https://www.biodiversitylibrary.org/item/103412

DOI: https://doi.org/10.1002/mmnd.48018840107

Permalink: https://www.biodiversitylibrary.org/partpdf/235312

\section{Holding Institution}

Harvard University, Museum of Comparative Zoology, Ernst Mayr Library

\section{Sponsored by}

Harvard University, Museum of Comparative Zoology, Ernst Mayr Library

\section{Copyright \& Reuse}

Copyright Status: Public domain. The BHL considers that this work is no longer under copyright protection.

This document was created from content at the Biodiversity Heritage Library, the world's largest open access digital library for biodiversity literature and archives. Visit BHL at https://www.biodiversitylibrary.org. 